\title{
Antioxidant Activity and Polyphenol Contents of Paris polyphylla Smith and Prospects of in situ Conservation
}

\author{
Warepam Jesmi Devi $^{1 *}$, J.M. Laishram ${ }^{1}$ and Supriyo Chakraborty ${ }^{2}$ \\ ${ }^{1}$ College of Agriculture, Central Agricultural University, India \\ ${ }^{2}$ Assam University Silchar, India
}

\begin{tabular}{l} 
K e y w o r d s \\
Paris polyphylla, \\
Cancer, \\
Antioxidant, \\
Micropropagation \\
\hline Article Info \\
\hline $\begin{array}{l}\text { Accepted: } \\
18 \text { April } 2018 \\
\text { Available Online: } \\
\text { 10 May } 2018\end{array}$ \\
\hline
\end{tabular}

A B S T R A C T

Cancer is a major public health burden in both developed and developing countries. Plant derived agents are being used for the treatment of cancer. Plants such as herbs have been used in folk medicine for centuries in most of the cultures throughout the world. The North Eastern regions of India are considered to be one of the biodiversity hotspots. Paris polyphylla (Paris polyphylla Smith. in Rees. Cyclop.26: paris n.2.1813; Hook.f., Fl. Britis India 6:362.1892., Liliaceae) is one of the indigenous medicinal plants of Manipur that have been used as medicine for over many years. The ground dried rhizomes of Paris polyphylla increases the surface area which enhance the rate of extraction using ethanol and petroleum ether for Soxhlet extraction techniques. The antioxidant activity by DPPH (1,1-diphenyl-2picrylhydrazyl) assay showed $68 \mu \mathrm{g} / \mathrm{ml}$ of the ethanol extract and the total phenol content by Folin's Ciocalteu reagent showed the presence of antioxidant property with a total phenol concentration of $0.68 \mathrm{mg} / \mathrm{g}$ catechol and $0.47 \mathrm{mg} / \mathrm{g}$ catechol with the ethanol and petroleum ether extracts respectively. Regarding the valuable usage of Paris polyphylla, the tissue culture from the rhizome explant was conducted on Murashige and Skoog (MS) media supplemented with $20.0 \mathrm{~g} / \mathrm{l}$ sucrose, $8.0 \mathrm{~g} / \mathrm{l}$ agar with different concentrations of 6benzylaminopurine (BAP), a-naphtaleneacetic acid (NAA) and Kinetin (KIN) to find a standard protocol for its mass production. The medium MS $+2 \mathrm{mg} / \mathrm{l} \mathrm{BAP}+$ $2 \mathrm{mg} / \mathrm{l} \mathrm{NAA}+2.5 \mathrm{~g} / \mathrm{l}$ Activated charcoal gave the best result of shoot regeneration. The findings also pointed to the possibility of consistent mass production of reliable planting materials like medicinal herbs for large scale in vitro micropropagation that may greatly help in pharmaceutical companies.

\section{Introduction}

Manipur is a land blessed with high biological diversity, which enclosed over a number of plant species, with some of them are unique only to Manipur. Among them most of the trees, shrubs and herbs are reported to have medicinal properties. The beneficial medicinal effects of plant materials typically result from the secondary products in the plant. Many biologically active plant-derived compounds were discovered as a result of chemical studies through isolation of active compounds from traditional medicine. Our Manipur flora represents a huge, barely untapped reserve of natural resources which is believed to contain substances with therapeutic potentials that yet to be explored. 
Plants are a source of large amount of drugs comprising to different groups such as antispasmodics, emetics, anti-cancer, antimicrobials etc. A large number of the plants are claimed to possess the antibiotic properties in the traditional system and are also used extensively by the tribal people worldwide. It is now believed that nature has given the cure of every disease in one way or another. Plants have been known to relieve various diseases in Ayurveda. Therefore, the researchers today are emphasizing on evaluation and characterization of various plants and plant constituents against a number of diseases ranging from diarrhoea to cancer.

Extraction of the bioactive plant constituents has always been a challenging task for the researchers. In this project, an attempt has been made to give an overview of certain extractants and extraction processes of Paris polyphylla along with the possibility of consistent mass production of reliable planting materials like medicinal herbs for large scale in vitro micropropagation that may greatly help in pharmaceutical companies.

\section{Paris polyphylla}

Paris polyphylla smith locally known as Singpan by Manipuris, Satwa by Garhwalis of Utterakhand, Satuwa by Nepalese of Nepal is an important member of this genus. It is a glaborous herb, perennial in nature growing in light sandy and humus rich soil with full or partial shade.

The genus name is derive from 'pars' referring to the symmetry of the plant. The species polyphylla means many leaves; poly meaning many and phyla meaning leaves. It grows upto 1 metre tall with very odd flower with long yellow radiating anthers. Its leaves grow in a single whorl below a flower growing in two whorls.

\section{Morphology}

The herb has an aerial herbaceous erect stem with a rhizome, leaves whorled of 6 to 12 slender, pointed, 3-7 inches green leaves with smooth margin. Venation parallel reticulate shape lanceolate. Above this whorled foliage there is a yellow green spider like flower. Inflorescence solitary terminal and not subtended by a leaf sheath. Flower bisexual regular, periapt of two series, sepaloid outer larger and inner smaller, tepal 3, 4 or 5. Androceum 6-11, stamens free.

Gynoecium1 pistil, 3-4 carpels, syncarpous, ovary superior. It blooms in the month of JulyAugust. The flower may last up to 3 months, ultimately displaying spherical $3 / 4$ inch green capsules which split when ripe in the late summer to reveal tiny red seeds. A mature fruit contain 50-60 seeds (Singh et al., 2008).

\section{Geography and distribution}

The genus is found growing in Europe, East Asia and Himalayan regions. Paris is found extensively growing in China with the Yunnan-Guizhou plateau as the centre of diversity (Ji et al., 2006). Paris polyphylla is found in growing in China, Bhutan and Nepal. In India, it is reported to be found growing in Manipur (Imphal), Uttarakhand (Tiwari. et al 2010), Himachal Pradesh and in Lushai and Aka Hills. In Manipur, the plant is found growing in Hengbung, Maram, Purul, Ukhrul, Makui regions of Senapati district and Puilong of Tamenglong district.

\section{Folk medicine}

The rhizomes of Paris polyphylla have been used as an anti-helminthic and vermifuge in folk communities of Nepal. The powdered roots of this plant are used as ethnopediatries for diarrhoea in Garhwal Himalaya, Uttarakhand. Paris polyphylla var. Chinesis and Paris polyphylla var. yunanesis are the 
two famous folk drugs. The major actions are given in the table 1 .

\section{Traditional uses}

Traditional medicinal uses of the plant by North Eastern people of India are not reported but Chinese has been using this plant as traditional medicine. Rhizoma Paridis or Chonglau [which refers to the roots or rhizomes of Paris polyphylla var yunanensis (Franch) HandMazz or Paris polyphylla Smith var chinesis (Franch) Hara of Liliaceae family] is widely used in traditional Chinese medicine for anti-febrile, alexipharmic, detumescent, demulsent, haemostatic and the treatment of haemopathy. It has been used to treat traumatic bleeding, inflammation, microbial infection and over the past decade, the cancer (Xiao et al 2009).

Rhizoma Paridis is the main component od Yun-bai-yao powder, Ji-deseng-she-yaopain tablets and Gongxuening capsules which are well known prepared Chinese medicines. Rhizoma Paridis has frequently played an important role in clinics of immunity adjustment and treating fractures, aprotitis, tumours, analgesia and bleeding (Zang et al., 2010). Also it has exhibited a variety of biological activities in heart and vascular malady, anti-fertility and spermicidal enhancement and sedatives.

Gongxuening capsules have been widely used for 10 years and are commercially available in most cities of China. Classically, this patent medicine has been used to cure female patients suffering from metrorrhgia, menorrhagia, metrostaxis, functional uterine bleeding and chronic pelvic inflammatory diseases (Liu et al., 2009).

The whole plant is used as febrifuge and the root posses healing properties like analgesic, antiphlogistic, anti-spasmodic, antitussive, depurative and narcotic. A decoction of roots is used in the treatment of poisonous snake bites, boils, ulcers and diphtheria and Japanese B encephalitis.

The plant has its ethnoveterinary uses for fever, stomach disorder and shoulder wounds for Oxen. And this plant extract is used for the same by the people of Uttarakhand.

\section{Warning/precaution}

Paris polyphylla is generally safe. However pregnant or lactating women should refrain from using the herb unless stated by their general medicine practitioner.

\section{Anti-oxidant}

The body's cells face formidable threats, from lack of food to infection with a virus. Another constant threat comes from nasty chemicals called free radicals. They are capable of damaging cells and genetic material. These free radicals are capable of attacking the healthy cells of the body. This may lead to damage, disease and severe disorders. Cell damage caused by free radicals appears to be a major contributor to aging and diseases like:

Cancer, heart disease, decline in brain function, decline in immune system etc.

The body generates free radicals as the inevitable by products of turning food into energy. Others are in the food you eat and the air you breathe. Some are generated by sunlight's action on the skin and eyes (Table 2).

An antioxidant is a molecule that inhibits the oxidation of other molecules. Oxidation is a chemical reaction that transfers electrons or hydrogen from a substance to an oxidizing agent. Oxidation reactions can produce free radicals. In turn, these radicals can start chain reactions. When the chain reaction occurs in a cell, it can cause damage or death to the cell. 
Antioxidants terminate these chain reactions by removing free radical intermediates, and inhibit other oxidation reactions.

In other words antioxidants are substances that may protect cells from the damage caused by unstable molecules known as free radicals. Free radical damage may lead to cancer. Antioxidants interact with and stabilize free radicals and may prevent some of the damage free radicals might otherwise cause. There are hundreds, probably thousands, of different substances that can act as antioxidants. The most familiar ones are vitamin $\mathrm{C}$, vitamin $\mathrm{E}$, beta-carotene, and other related carotenoids, along with the minerals selenium and manganese. They are joined by glutathione, coenzyme Q10, lipoic acid, lycopene, flavonoids, phenols, polyphenols, phytoestrogens, and many more.

\section{Integrative cancer therapies}

\section{Antioxidants in cancer therapy}

While the efficacy of antioxidants during cancer treatment is still being evaluated and clinical trials are ongoing or being set up, many cancer patients who are undergoing therapy take antioxidant supplements in an effort to alleviate treatment toxicity and improve longterm outcome. The modulating effects of antioxidants in treatment depend on a wide range of factors, including the metabolic state of the patient, the stage and site of the disease, and the modality being used. In contrast to radiation treatment, which interacts with the target tissue within a fraction of a second and is gone, producing damage at the time of treatment, agents used in chemotherapy are not confined to the target tissue; they prevail in the body for some time and can interact with and damage a plethora of cellular molecules at different sites for longer periods of time, depending on metabolism, increasing lipid peroxidation of molecules, reducing antioxidant levels, and enhancing oxidative stress (Sangeetha et al., 1990).

The primary focus of radiation therapy and chemotherapy is to produce irreversible DNA damage in tumor cells that will prevent their replication and lead to their demise. Another course of action is to alter cellular homeostasis and modify signal transduction pathways, redox state, and disposition to apoptosis. The cellular changes would, ideally, enhance tumor cell killing, largely by apoptosis, and reduce the probability of normal cell death. Antioxidant protection of normal cells, however, would occur, in principle, in all treatments, even when the mechanism of the chemotherapeutic drug is independent of free radical action; antioxidants help maintain the health of normal tissues and protect them from the toxic effects of free radical-producing cytokines that circulate in cancer patients and increase with the severity of the disease (Sozen et al., 2004).

Antioxidants do reduce the painful side effects of radiation and chemotherapy, thus supporting the beneficial effects of antioxidants in protecting normal cells during treatment and acting as adjuvants in the treatment of certain cancers. It is doubtful whether taking antioxidant supplements at government-recommended doses (recommended dietary allowance) would hinder therapy, given the high doses of radiation and anticancer drugs that are used in treatment, which deplete endogenous antioxidants; there is good evidence that antioxidants would protect normal cells during treatment and prevent treatment-associated adverse side effects.

Experimental studies show that antioxidants, including phytochemicals, selectively kill cancer cells by apoptosis while preventing apoptosis in normal cells, in vitro and in vivo, and inhibiting tumor angiogenesis and metastatic growth. Additional studies are needed to shed light on the use of antioxidants in the prevention and therapy of human 
cancer. Most radiation oncologists counsel their patients to refrain from taking antioxidant supplements during cancer therapy; others, however, consider the available data and suggest that a cautious and judicious use of antioxidants that helps the patient maintain a good quality of life is useful in cancer treatment.

\section{Materials and Methods}

\section{Biochemical analysis}

\section{Extraction of bioactive compounds}

Extraction (as the term is pharmaceutically used) is the separation of medicinally active portions of plant (and animal) tissues using selective solvents through standard procedures. The products so obtained from plants are relatively complex mixtures of metabolites, in liquid or semisolid state or (after removing the solvent) in dry powder form, and are intended for oral or external use. These include classes of preparations known as decoctions, infusions, fluid extracts, tinctures, pilular (semisolid) extracts or powdered extracts. Such preparations have been popularly called galenicals, named after Galen, the second century Greek physician (Remington, 773-774).

Extraction methods used pharmaceutically involves the separation of medicinally active portions of plant tissues from the inactive/inert components by using selective solvents. During extraction, solvents diffuse into the solid plant material and solubilize compounds with similar polarity (Ncube et al., 2008).

The purpose of standardized extraction procedures for crude drugs (medicinal plant parts) is to attain the therapeutically desired portions and to eliminate unwanted material by treatment with a selective solvent known as menstrum. The extract thus obtained, after standardization, may be used as medicinal agent as such in the form of tinctures or fluid extracts or further processed to be incorporated in any dosage form such as tablets and capsules. These products contain complex mixture of many medicinal plant metabolites, such as alkaloids, glycosides, terpenoids, flavonoids and lignins (Handa et $a l ., 2008)$. The technique used in this process was Soxhlet extraction technique where the desired compound has a limited solubility in a solvent, and the impurity is insoluble in that solvent. If the desired compound has a high solubility in a solvent then a simple filtration can be used to separate the compound from the insoluble substance. The advantage of this system is that instead of many portions of warm solvent being passed through the sample, just one batch of solvent is recycled. This method cannot be used for thermolabile compounds as prolonged heating may lead to degradation of compounds (Nikhal et al., 2010).

\section{Steps of Soxhlet extraction process}

1. Dried rhizomes of Paris polyphylla smith were ordered and collected from a renowned Herbarium named SHIDAHIDAK, Phumlou Shiphai, Imphal, Manipur.

2. The dried rhizomes were then ground into coarse particles to increase the surface area for extraction process.

3. Weighed $100 \mathrm{~g}$ of the dried powder and were put into an extraction thimble (Whatman no.1)

4. The filled thimbles were then placed into the Soxhlet apparatus.

5. $1000 \mathrm{ml}$ of solvents such as ethanol and petroleum ether each were used for the extraction.

6. Both the extractions were carried out for 7 to 8 hours at $50 \mathrm{oC}$ to $60 \mathrm{oC}$, then the solvent was evaporated to dryness.

7. The residues were then dissolved in $10 \mathrm{ml}$ distilled water, its dilution was for the biochemical analysis such as antioxidant 
activity and total phenol contents.

Antioxidant activity by DPPH assay (petroleum ether and ethanol extracts)

The DPPH free radical is reduced to a corresponding hydrazine when it reacts with hydrogen donors.

The DPPH radical is purple in color and upon reaction with a hydrogen donor changes to yellow in color. It is a discoloration assay, which is evaluated by the addition of the antioxidant to a DPPH solution in ethanol or methanol and decrease in absorbance is measured at $517 \mathrm{~nm}$.

\section{Preparation of plant extract}

Powdered sample were extracted with petroleum ether and with ethanol (80\%), solvent evaporated to dryness and then subjected to determination of total phenolic content and antioxidant activity.

\section{Materials required}

UV-visible, Cecil CE 7200, 7000 series spectrophotometer, 2, 2-diphenyl -1 picrylhydrazyl (DPPH), HI MEDIA laboratories ltd, Mumbai, Ascorbic acid.

The free radical scavenging activity of ethanol extract of Paris polyphylla was measured by1, 1-diphenyl-2-picryl-hydrazil (DPPH) assay. $0.1 \mathrm{mM}$ solution of DPPH in ethanol was prepared and $1 \mathrm{ml}$ of this solution was added to $3 \mathrm{ml}$ of various concentrations of MEMC and the reference compound $(10-150 \mu \mathrm{g} / \mathrm{ml})$. After $30 \mathrm{~min}$, absorbance was measured at $650 \mathrm{~nm}$. Ascorbic acid $(25 \mu \mathrm{g})$ was used as the reference material.

All the tests were performed in triplicate and the graph was plotted with the mean values. The percentage of inhibition was calculated by comparing the absorbance values of the control and test samples.

Estimation of total phenolic content by Folin's Ciocalteu reagent

Phenols react with phosphomolybdic acid in Folin Ciocalteu reagent in alkaline medium and produce blue coloured complex (molybdenum blue).

Solution of $1 \mathrm{mg} / \mathrm{ml}$ of Catechol was prepared in distilled water. From this various concentrations ranging from $10-50 \mu \mathrm{g} / \mathrm{ml}$ were prepared. To this $0.5 \mathrm{ml}$ Folin Ciocalteu reagent was added and kept for 3 min and then $3 \mathrm{ml}$ of $20 \%$ sodium carbonate solution was added and made up to $6 \mathrm{ml}$ with distilled water. The mixture was kept for $30 \mathrm{~min}$ and absorbance was measured at $650 \mathrm{~nm}$ respectively. Catechol $(100 \mathrm{mg} / \mathrm{ml})$ was used to produce standard calibration curve. The total phenolic content was expressed in $\mathrm{mg}$ of Catechol equivalents (CE) / $g$ of extract.

\section{Micropropagation}

Preparation of MS media with different concentrations of plant hormones is given in Table 3.

\section{Results and Discussion}

\section{Biochemical analysis}

\section{Antioxidant activity and total phenol contents}

Antioxidants have been shown to play an important role in preventing many diseases like cancer, inflammation and brain dysfunction (Adesegun et al., 2009). The interests in phenolic compounds, particularly flavanoids and tannins have considerably increased in recent years because of their broad spectrum of chemical and diverse biological properties. Thorough phytochemical investigations and evaluation 
for their antioxidant activity by means of various in vitro biochemical assays have to be carried out to characterize the bioactive compounds with potential antioxidant activity (Ajitha and Rajnarayana et al., 2001). The aim of the present study was to carry out the determination of total phenolic content in the petroleum extract and ethanolic extract of Paris polyphylla and its antioxidant activity.

Other study showed that the highest antioxidant activity, total phenolic content and total flavonoid content were exhibited by the extracts obtained by high pressure extraction with ethyl acetate as solvent. It has been reported that $M$. citrifolia fruit contains relatively larger quantity of non-polar antioxidant compounds. However, among the ethylacetate extracts spray dried extract exhibited highest antioxidant activity and total flavonoid content and vacuum dried, the highest total phenolic content. This may be due to the different drying methods used.

It is interesting to note that the ultrasonic extracts at $24 \mathrm{KHz}$ in ethanol and vacuum dried exhibited significant antioxidant activity, total phenolic content and flavonoid content comparable to ethyl acetate extracts. Further work is possible on finding the optimum frequency for the separation of phytochemicals from the fruit matrices of Morinda citrifolia L. Comparatively, least activity were expressed by the ethanol extracts. It can be said that the polarity of the solvent had significant impact on the extraction of phytochemicals such as antioxidants, phenolics and flavonoids from the fruit matrices of Morinda citrifolia L (Astley et al., 2003). In this study, the ethanolic extract of $P$. polyphylla showed prominent inhibition concentration value of $68 \mu \mathrm{g} / \mathrm{ml}$ by DPPH method and the standard ascorbic acid showed an inhibition concentration value of $7.8 \mu \mathrm{g} / \mathrm{ml}$ by $\mathrm{DPPH}$ method. And the total phenolic content was found to be $0.47 \mathrm{mg} / \mathrm{g}$ catechol from petroleum ether extract and $0.68 \mathrm{mg} / \mathrm{g}$ catechol from ethanol extract which indicate that the ethanol extract has higher total phenolic content. Thus, exhibit significant antioxidant activity.

\section{Micropropagation}

\section{Induction of shoots of Paris polyphylla}

\section{Initiation of shoot buds}

Establishment of contamination free cultures was a major task due to the fact that the explants originated from underground rhizomes. In this study, rhizomes were initially sprouted on soil free condition until shoot buds appeared. These shoot buds were excised from rhizomes and were used as explants. The buds from the rhizomes of P.polyphylla that were surface sterilized with mercuric chloride $\left(\mathrm{HgCl}_{2}\right)$ solution for $15 \mathrm{~min}$ could establish more than $70 \%$ aseptic and surviving explants and remained free of contamination after four (4) weeks in MS medium. Chan and Thong (2004) also reported that the use of $\mathrm{HgCl}_{2}$ with two-stage surface sterilization using Tween 20 solution was extremely efficient for establishing aseptic buds of other Liliaceae species. Similar sterilization process was also used to establish the aseptic buds of Cymbopogon nardus (Chan et al., 2005). Once the contamination free cultures of the shoot buds were established, they were easily maintained by sub culturing on fresh medium.

\section{Shoots growth and multiplication}

The aseptic shoots of $P$. polyphylla cultured on MS medium supplemented with different concentrations of BAP alone (0.5 to $2.5 \mathrm{mg} / \mathrm{l})$ or in combinations with NAA $(0.0$ and 2.0 $\mathrm{mg} / \mathrm{l})$ resumed their growth, produced shoots and roots, simultaneously (Table 3). The simultaneous production of shoots and roots were also reported in other 
Table.1 Major functions of drugs of Paris polyphylla

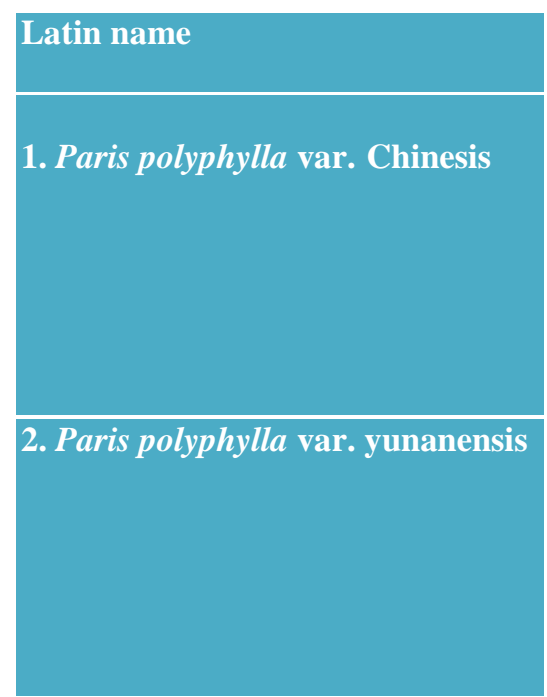

Chinese name
1. Qiyeyizhihua
2. Zaoxiu (Shen Nong Ben Cao
Jing, AD 22-250)
3. Chonglou (Tang Ben Cao, AD
659)
4. Ziheche (Ben Cao Gang Mu, AD
1540)

1. Dianchonglau

2. Chonglau (Dian Nan Ben Cao, AD 1370)

\section{Major actions}

a.Treatment of snake bite

b. Antibiotic

c. Anti tumour

d. Contraceptive

e. Sedative

Table.2 Principal antioxidants and their interactions

\begin{tabular}{|c|c|}
\hline Antioxidant & Interaction \\
\hline $\begin{array}{l}\text { Vitamin C } \\
\text { Vitamin E }\end{array}$ & $\begin{array}{l}\text { Regenerates active } \alpha \text {-tocopherol } \\
\text { (vitamin E) by reducing its radical } \\
\text { form. } \\
\text { Transport and storage depend on } \\
\text { selenium; absorption is reduced } \\
\text { when vitamin A and } \beta \text {-carotene } \\
\text { levels are high } \\
\text { Conversion to vitamin A requires } \\
\text { vitamin E } \\
\text { Synergistic with vitamin } E\end{array}$ \\
\hline
\end{tabular}

Data from Borek
a. Hemostasis
b. Anti tumour
c. Antibiotic
d. Treatment of trauma
e. Antiparotitis

Table.3 MS media supplemented with different concentration of BAP, NAA and KIN along with activated charcoal on multiple shoots formations of $P$. polyphylla smith

\begin{tabular}{|c|c|c|c|c|c|}
\hline Treatment & $\begin{array}{c}\text { BAP (Stock } \\
\text { Solution) }(\mathrm{ml} / \mathrm{l})\end{array}$ & $\begin{array}{c}\text { NAA (Stock } \\
\text { solution) }(\mathrm{ml} / \mathrm{l})\end{array}$ & $\begin{array}{c}\text { KIN (Stock } \\
\text { solution) }(\mathrm{ml} / \mathrm{l})\end{array}$ & $\begin{array}{c}\text { Activated } \\
\text { Charcoal }(\mathrm{g} / \mathrm{l})\end{array}$ & $\begin{array}{c}\text { Shoot regeneration } \\
\text { in }(\%) *\end{array}$ \\
\hline 1 & 0.5 & 0.0 & 1.0 & 0.0 & 0 \\
\hline 2 & 0.5 & 2.0 & 0.0 & 2.5 & 5 \\
\hline 3 & 1.0 & 0.0 & 1.0 & 0.0 & 20 \\
\hline 4 & 1.0 & 2.0 & 0.0 & 2.5 & 40 \\
\hline 5 & 1.5 & 0.0 & 1.0 & 0.0 & 45 \\
\hline 6 & 1.5 & 2.0 & 0.0 & 2.5 & 48 \\
\hline 7 & 2.0 & 0.0 & 1.0 & 0.0 & 52 \\
\hline 8 & 2.0 & 2.0 & 0.0 & 2.5 & 30 \\
\hline 9 & 2.5 & 0.0 & 1.0 & 0.0 & 10 \\
\hline
\end{tabular}

*values represent the percentage of shoot growth per 15 treatments after 4 weeks of culture. 
Fig.1 a) Dried rhizomes of $P$. polyphylla. b) Powdered rhizomes of $P$. polyphylla.
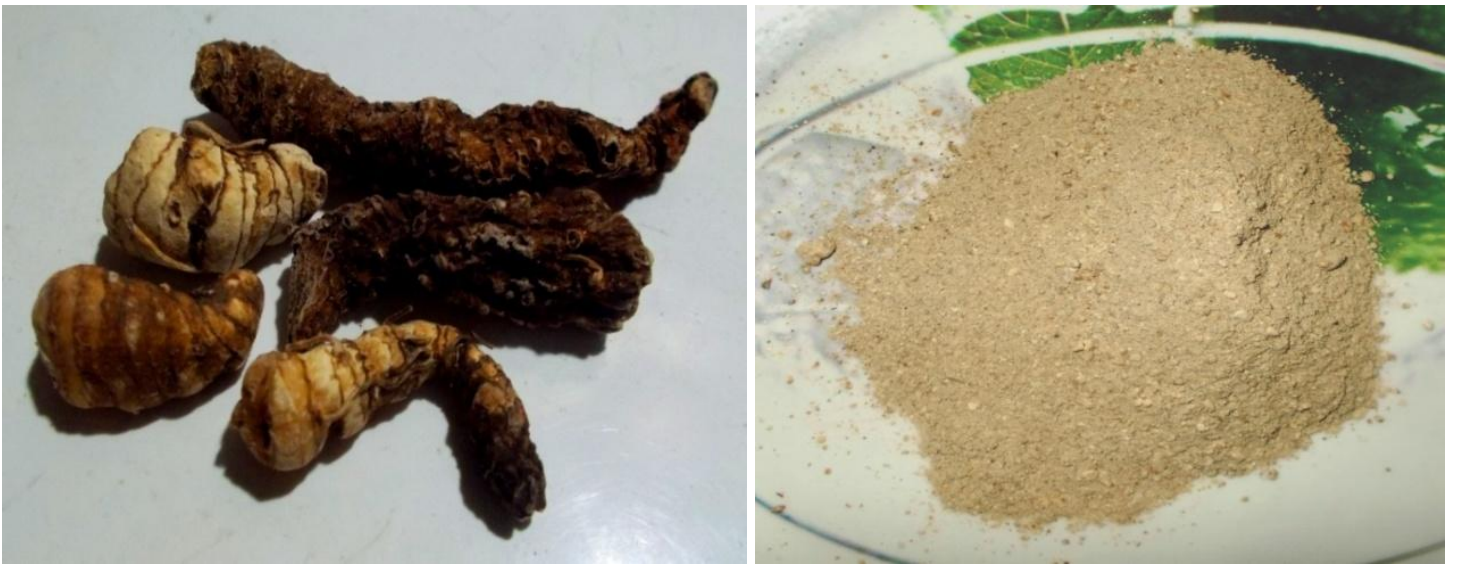

Fig.2 a) Extracted samples $P$. polyphylla b) Evaporated samples of $P$. polyphylla
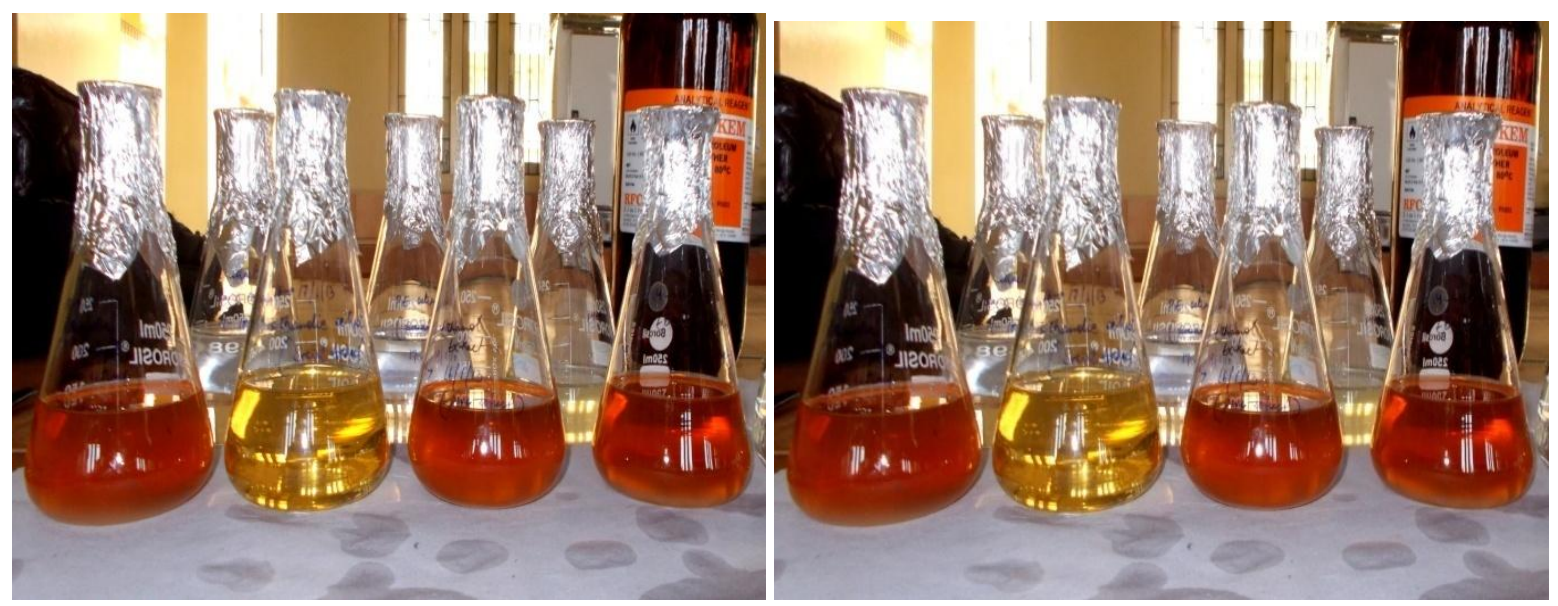

Fig.3 Determination of phenolic content by Folin's Ciocalteu reagent

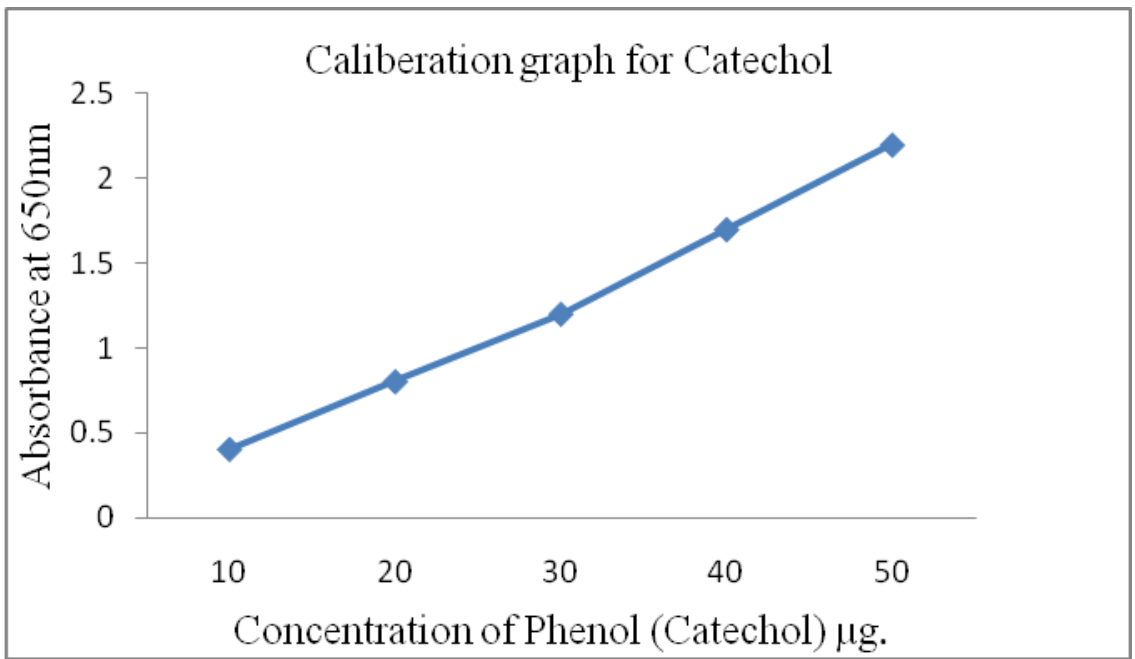


Fig.4 Antioxidant activity of $P$. polyphylla by DPPH method

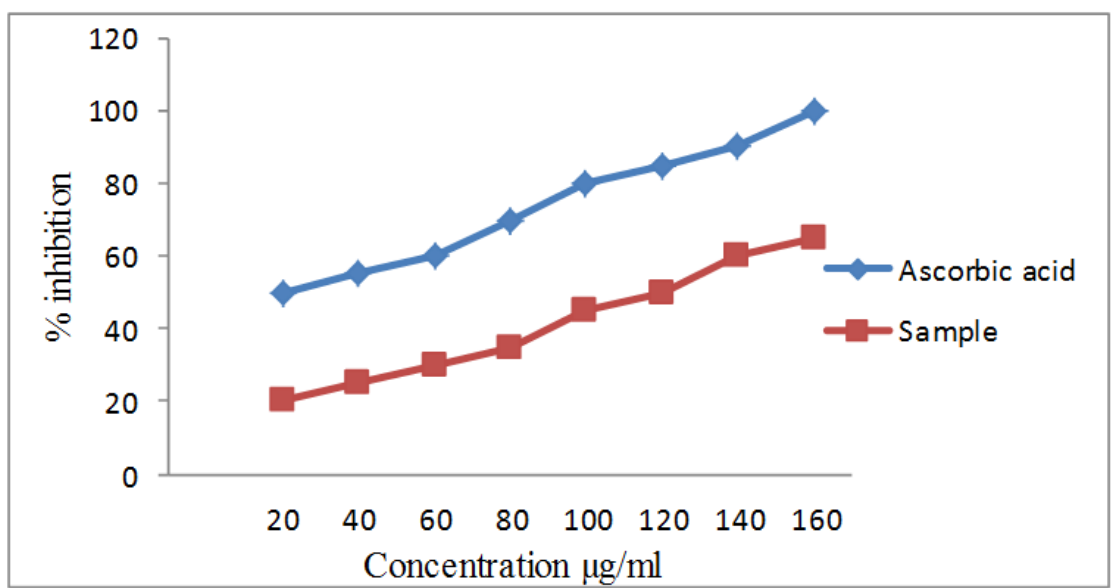

Fig.5 a) in 7 days (a week) b) in 15 days c) in 30 days (month)
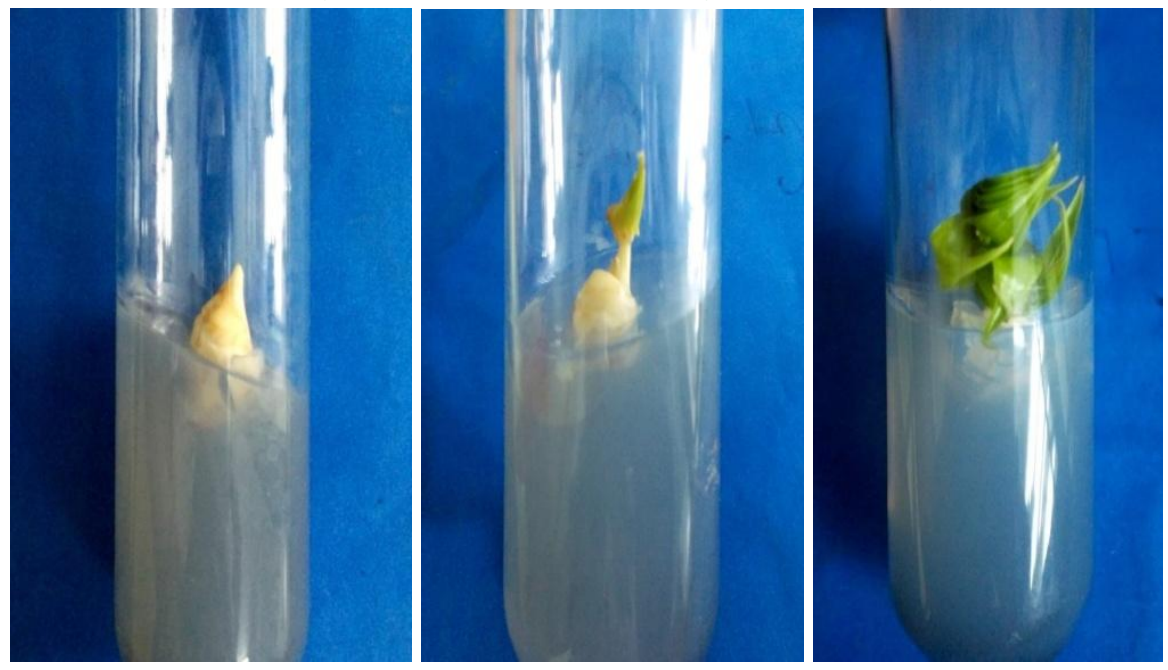

Fig.6 Effects of MS medium supplemented with $\operatorname{BAP}(0.5,1.0,1.5,2.0$ and $2.5 \mathrm{mg} / \mathrm{l})$, low concentration of NAA ( $2.0 \mathrm{mg} / \mathrm{l})$ along with Activated charcoal $(2.5 \mathrm{~g} / \mathrm{l})$ on shoots formation of $P$. polyphylla over a period of four (4) weeks of culture. Values are percentage for 15 cultures per treatments

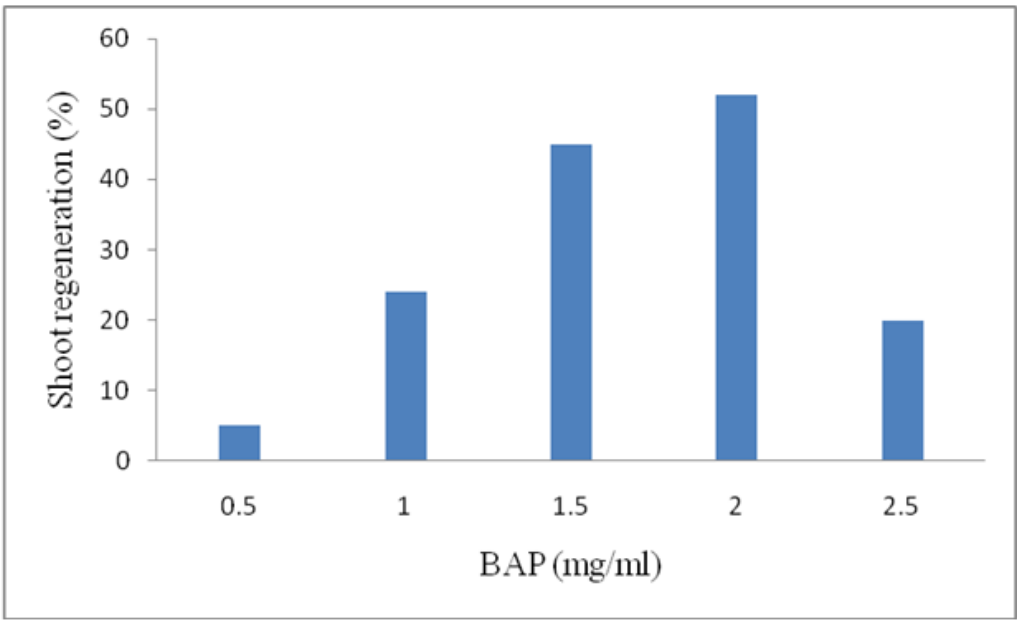


Liliaceae species (Balachandran et al., 1990; Chan and Thong, 2004; Bharalee et al., 2005). The growth of the shoots and subsequent multiplication could not be achieved in medium without growth regulators. After 4 to 6 weeks, about $52 \%$ of the shoots of P.polyphylla that were cultured on MS medium supplemented with 0.5 to $2.5 \mathrm{mg} / \mathrm{l}$ of BAP and 0.0 to $2.0 \mathrm{mg} / \mathrm{l} \mathrm{NAA}$ showed different levels of development with high micropropagation frequency and variable number of leaves.

The maximum number of shoots regeneration was obtained in the MS medium containing 2.0 $\mathrm{mg} / \mathrm{l}$ of BAP and $2.0 \mathrm{mg} / \mathrm{l} \mathrm{NAA}$ along with activated charcoal, four (4) weeks after culture initiation (Table 3). In literatures regarding micropropagation of $P$. polyphylla reveals that there is low success rate in cultures, though in this study trials of growth regeneration were carried out from rhizomes cutting and found that shoots got regenerated in MS medium containing $(\mathrm{MS}+2.0 \mathrm{mg} / \mathrm{ml} \mathrm{BAP}+2.0 \mathrm{mg} / \mathrm{ml} \mathrm{NAA}+$ Activated Charcoal and for cloning micropropagation no multiple shoots were obtained as such. Balachandran et al., (1990) also reported that higher concentration of kinetin was not suitable for Zingiber officinale. Aseptic cultures in MS supplemented with $2.0 \mathrm{mg} / \mathrm{l} \mathrm{BAP}$ and $1.0 \mathrm{mg} / \mathrm{l}$ NAA induced more roots than shoots.

The bulb of Bowiea volubilis (Liliaceae) is important in traditional medicine in South Africa. Although this species can be macro- and micropropagated, present methods relying on the use of bulb-scale pieces can result in the destruction of the parent plant. In this study, a protocol for the organogenic plant regeneration from inflorescence pieces was established. It involves the culture of $10 \mathrm{~mm}$ long pieces of inflorescence stem on MS basal nutrient medium, $30 \mathrm{~g} \mathrm{l}^{-1}$ sucrose, $10 \mathrm{~g} \mathrm{l}^{-1}$ agar, $1 \mathrm{mg} \mathrm{l}^{-1}$ 2,4-D and $1 \mathrm{mg} \mathrm{l}^{-1}$ BAP, in the dark for 6-8 weeks. The explants are then transferred to fresh medium without growth regulators, where bulblet development, shoot elongation and rooting occur within 4-5 weeks. Successful hardening-off is achieved using conditions of relatively low humidity. As the inflorescence is very long (up to $20-30 \mathrm{~m}$ in total) and the protocol results in approximately 4.6 plantlets per explant, thousands of plantlets can potentially be produced in this manner from a single inflorescence (Hannweg et al., 1996).

Micropropagation protocols for cloning of some medicinal plants such as Catharanthus roseus (Apocynaceae), Chlorophytum borivilianum (Liliaceae), Datura metel (Solanaceae), and Bacopa monnieri (Scrophulariaceae) have been developed. Regeneration occurred via organogenesis and embryogenesis in response to auxins and cytokinins. The integrated approaches of our culture systems will provide the basis for the future development of novel, safe, effective, and high-quality products for consumers (Debnath et al., 2006).

It is concluded from the experiments conducted to determine the antioxidant activities and total phenolic compounds in P. polyphylla Smith revealed that both ethanol and petroleum ether extracts content high amount of total phenolic compound which indicated that $P$. polyphylla Smith content high amount of total phenolic compound which in turn exhibit significant antioxidant activities in the plant metabolism. This may indicate that further research to determine active chemical compounds against cancer in $P$. polyphylla Smith is very necessary. This will enhance the importance of bioresources of medicinal plants of the North East India. The medicinal plant Paris polyphylla Smith has been widely collected by local population for unauthorized trade in China where the plant is supposed to be used as plant extract against breast tumor. Thus the population of this plant has been tremendously depleted and is at the verge of extinction. Hence micropropagation protocols have to be developed for micropropagation of this plant for introduction to the specific locations for in situ presentation. The results revealed that $\mathrm{MS}$ basal medium supplemented with $2.0 \mathrm{mg} / \mathrm{l} \mathrm{BAP,} 2.0 \mathrm{mg} / \mathrm{l} \mathrm{NAA}$ and $2.5 \mathrm{~g} / \mathrm{l}$ activated charcoal gave the best result for shoot and root regeneration of Paris polyphylla Smith (Fig. 1-6). 


\section{Acknowledgement}

I take this precludes to express my sincere gratitude to my industry guide DR.J.M.LAISHRAM, Professor and Head of Department of Plant Breeding and Genetics, Central Agricultural University, Iroisemba, Imphal for his dynamic guidance and tireless supervision. I also extend my sincerest gratitude to my faculty guide Dr.V.Pooja, Assistant Professor of Amity Institute of Biotechnology (AIB), Amity University, Noida for her timely acceptance of my project title, without her acceptance. I am also very thankful to Thangjam Surchandra Singh, Junior Research Fellow (JRF), Department of Plant Breeding and Genetics for his dynamic help and guidance at every step of my research work to make it a complete successful project.

\section{References}

Xiao. X., Bai. P., Nguyen., T.M.B., Xiao. J., Yang. G. Hu. L., Chen. X., Zhang. X., Liu. J., Wang. H.: The antitumoral effect of Paris Saponin I associated with the induction of apoptosis through themitochondrial pathway. Mol cancer Ther. 8(5):1179-1188(2009).

Zang. T., Liu. H., Liu Xue. T., Xu. D., Chen. X, Wang. Q., ; Qualitative and quantitative analysis of steroidal saponins in crude extracts from Paris polyphylla var. yunnanensis and $P$. polyphylla var. chinensis by high performance liquid chromatography coupled with mass spectrometry. Journal of Pharmaceutical and Biomedical Analysis 51(1), 114124(2010).

Adesegun S.A., Fajana A., Orabueze C.I. and Coker H.A.B. Evaluation of antioxidant properties of Phaulopsis fascisepala C.B.Cl. (Acanthaceae), eCAM. 2009, 6, 227-231.

Ajitha $\mathrm{M}$ and Rajnarayana K. Indian Drugs. 2001, 38, 545-554.

American Cancer Society. ACS statistics 2004. Available at: http://www.cancer. org. Accessed August 25, 2004.
Astley, S. B. (2003). Dietary antioxidants - past, present and future? Trends in Food Science and Technology, 14, 93-98.

Balachandran SM, Bhat SR, Chandel KPS (1990). In vitro clonal multiplication of turmeric (Curcuma spp) and ginger (Zingiber officinale Rosc). Plant Cell Rep. 8:521-524.

Bharalee R, Das A, Kalita MC (2005). In vitro clonal propagation of Curcuma ceasia Roxb. and Curcuma zedoaria Rosc. From rhizome bud explants. J. Plant Biochem. Biotechnol. 14: 61-63.

Borek C. Antioxidants and cancer. Sci Med (Phila). 1997; 4: 51-62.

Casciari J.J. Riordan N.H. Schmidt T.L. Meng X.L. Jackson J.A. Riordan H.D. (2001) Cytotoxicity of ascorbate, lipoic acid, and other antioxidants in hollow fibre in vitro tumours, $\mathrm{Br} \mathrm{J}$ Cancer, 84(11), 1541-1550.

Chan L, Devi PR, Boey PL (2005). Effect of plant growth regulators on regeneration of plantlets from bud cultures Cymbopogon nardus L. and the detection of essential oils from the in vitro plantlets. J. Plant Biol. 48: 142146.

Cooke MS, Evans MD, Dizardaroglu M, Lunec J. Oxidative DNA damage: mechanisms, mutation and disease. FASEB J 2003;17:1195-214.

Debnath M, Malik CP, Bisen PS; 2006 Feb; Micropropagation: a tool for the production of high quality plant-based medicines. Curr Pharm Biotechnol. 7(1): 33-49.

Handa SS, Khanuja SPS, Longo G, Rakesh DD. Extraction Technologies for Medicinal and Aromatic Plants. International centre for science and high technology, Trieste, 2008, 21-25.

Hickey S. Roberts H.J. (2007) Selfish cells: cancer as microevolution, Pp. 137-146.

Ji, Y., Fritsch, P.W., Li. H., Xiao. T., Zhou. Z: Phylogeny and classification of Paris (Melanthiaceae) inferred from DNA sequence data. Anals of Botany 98:245256 (2006). 
K. Hannweg, M.P. Watt and P. Berjak., Centre for Indigenous Plant Use Research, Biology Department, University of Natal, Private Bag X10, Dalbridge 4014, Republic of South Africa (1996).

Kahkonen MP, Hopia AI, Vuorela HJ, Rauha JP, Pihlaja K, Kujala TS and Heinonen M (1999). Antioxidant activity of plant extracts containing phenolic compounds. J. Agric. Food Chem. 47: 3954-3962.

Liu, X.X., Wang. L., Yangi. T.T., Dengi. X.D., Wang Q,: Simultaneous analysis of eight bioactive steroidal saponins in Gongxuening capsules by HPLC-ELSD and HPLC-Msn. Acta Chromatographica 21(2): 327- 339 (2009).

Murashige T and Skoog T (1962), A revised medium for growth and boiassays with tobacco tissue cultures, Physiologia Plantarum 15:473-497.

Ncube NS, Afolayan AJ, Okoh AI. Assessment techniques of antimicrobial properties of natural compounds of plant origin: current methods and future trends. African Journal of Biotechnology 2008; 7 (12): 1797-1806.

Nikhal SB, Dambe PA, Ghongade DB, Goupale DC. Hydroalcoholic extraction of Mangifera indica (leaves) by Soxhletion. International Journal of Pharmaceutical Sciences 2010; 2 (1): 30-32.

Proestos C, Boziaris, I. S., Nychas, GJ E and Komaitis M (2006). Analysis of flavonoids and phenolic acids in Greek aromatic plants: investigation of their antioxidant capacity and antimicrobial activity. Food Chem. 95: 664-67.

Ravikumar P.R., Hammesfahr P. and Charles J. Cytotoxic saponins from the Chinese herbal drug Yunnan Baiyao [J]. J Pharm Sci, 1979, 68, 900.

Remington JP. Remington: The science and practice of pharmacy, 21st edition, Lippincott Williams \& Wilkins, 773774.

Sangeetha P, Das UN, Koratkar R, Suryaprabha $P$. Increase in free radical generation and lipid peroxidation following chemotherapy in patients with cancer. Free Radic Biol Med. 1990; 8: 15-19.

Sing S.B. and Raghunath S. Spirostanol saponins from Paris polyphylla structures of polyphylla C, D, E and F [J]. Phytochemistry, 1982, 21, 2925.

Singh, R.K.I Panmei, C., Devi, L.S., Shah S.A., Devi. K.T. Devi, Kh.S., Paris polyphylla smith. The wonder Herb: In Proceeding International Conclave in Medicinal Plants for ASEAN and BIMSTEC countries Dec 11-Dec 13, 2008, pp 82-86, Imphal, Manipur, India (2008).

Sozen S, Coskun U, Sancak B, et al., Serum levels of interleukin-18 and nitrite + nitrate in renal cell carcinoma patients with different tumor stage and grade. Neoplasma. 2004; 51: 25-29.

Watson J. (2013) Nobel laureate James Watson claims antioxidants in late-stage cancers can promote cancer progression. The Royal Society, latest news, 09 January, http://royalsociety.

org/news/2013/watson-antioxidantscancer

\section{How to cite this article:}

Warepam Jesmi Devi, J.M. Laishram and Supriyo Chakraborty. 2018. Antioxidant Activity and Polyphenol Contents of Paris polyphylla Smith and Prospects of in situ Conservation. Int.J.Curr.Microbiol.App.Sci. 7(05): 2355-2367. doi: https://doi.org/10.20546/ijcmas.2018.705.271 